\title{
Revisitando a produção científica nos anais do Encontro Nacional de Engenharia de Produção
}

\author{
Rosa Maria Villares de Souza Berto ${ }^{\text {a* }}$, Davi Nakano ${ }^{\mathrm{b}}$ \\ a*rosavillares@uol.com.br, USP, Brasil \\ bdnnakano@usp.br, USP, Brasil
}

\begin{abstract}
Resumo
Este trabalho finaliza um ciclo de investigações acerca das técnicas de pesquisa utilizadas e declaradas nos trabalhos publicados de 1996 a 2007 nos anais do Encontro Nacional de Engenharia de Produção - ENEGEP. A partir de reflexões sobre a importância da abordagem de pesquisa, a determinação e escolha dos tipos e técnicas de pesquisa, o conjunto de papers integrantes de 12 anos de edições consecutivas dos referidos anais foi analisado e classificado através de levantamento sistemático, de acordo com categorização proposta por Fillipini (1997). Os resultados indicaram o crescimento da pesquisa empírica mas a persistência de uma significativa diferença de perfil em relação à pesquisa internacional.
\end{abstract}

Palavras-chave

Metodologia científica. Métodos e técnicas de pesquisa. Engenharia de produção. Industrial engineering.

\section{Introdução}

Há 12 anos foi publicado neste periódico o primeiro levantamento contendo dados relativos às técnicas de pesquisa utilizadas nos trabalhos apresentados no Encontro Nacional de Engenharia de Produção - ENEGEP. 0 texto de Berto e Nakano (2000) compôs um retrato da produção acadêmica dos anos de 1996 a 1998 com o objetivo de descrever a utilização das técnicas de pesquisa, seguindo a preocupação com a aplicação de métodos na produção nacional, nascente à época. Trabalho posterior de Nakano (2011) atualizou os dados até 2004. Este artigo encerra o ciclo de observações, oferecendo uma visão longitudinal dos procedimentos de pesquisa utilizados na Engenharia de Produção de 1996 a 2007 cujos resultados foram comunicados através dos anais dos ENEGEPs. Além da perspectiva de evolução temporal, o texto permite discutir as possíveis modificações no perfil metodológico dos trabalhos, haja vista que durante o período de análise ocorreram dois fatos significativos no contexto da formação em Engenharia de Produção no Brasil e que podem ter causado impacto e mudanças ao processo relatado: o crescimento do número de programas de graduação em Engenharia de Produção e o aumento das exigências de produção científica dos programas de pós-graduação. Assim, o objetivo do presente texto é concluir a reflexão a respeito da evolução nas condutas de investigação relatadas nos trabalhos de pesquisa na área, apontando as tendências e oferecendo uma comparação com dados internacionais.

\section{Sobre metodologia da pesquisa}

0 processo de investigação científica contempla uma etapa de configuração do pacote metodológico, que deve ser idealizado e composto a partir da escolha de métodos e técnicas ajustados e coerentes com o problema e a questão de pesquisa, os pressupostos ou hipóteses construídas e os objetivos propostos. $\mathrm{Na}$ atividade de pesquisa, método e técnica (do grego, methodos: caminho e tékhne: arte) são complementares e indissociáveis, uma vez que o método indica o percurso e a técnica provê o transcurso até o resultado. 0 cuidado na composição do referido pacote deve ser 
análogo ao cuidado com que um cirurgião escolhe técnicas e instrumentos específicos e eficientes ao bom termo das intervenções cirúrgicas. Porém, adições significativas de eficácia e sucesso aos resultados ficam por conta do talento e expertise do pesquisador e de sua equipe.

No caso da metodologia científica é importante, em princípio, entender o propósito do estudo para que se escolha adequadamente o método (p.e.: indutivo, dedutivo, hipotético-dedutivo) a ser utilizado. A escolha do método condiciona a maneira como o problema de pesquisa será abordado. Por sua vez, a abordagem (p.e.: qualitativa, quantitativa) posiciona o pesquisador a olhar o fenômeno - objeto de análise - a partir e através de um foco consistente que possa estruturar, caracterizar e sustentar a conduta investigativa.

Não se deve esquecer que, apesar de todo o distanciamento crítico exigido nas pesquisas, não há como isentar os sentidos, as escolhas e as leituras feitas pelo investigador, pois

[...] todo ponto de vista é a vista de um ponto e para entender como alguém lê é necessário saber como são seus olhos e qual é a sua visão do mundo [...] (BOFF, 2002, p. 9).

Assim sendo, aspectos como visão de mundo, relação entre o pesquisador e o objeto pesquisado, relação entre fatos e valores objetivos e subjetivos são determinantes para a escolha da abordagem e terão reflexo direto no desenho e foco da pesquisa assim como nos seus objetivos, na construção de hipóteses ou pressupostos, no tipo e perfil da amostra, instrumentos de coleta e tratamento dos dados (TURATO, 2005).

Muitas vezes, o entendimento conceitual das abordagens de pesquisa (quantitativa, qualitativa e qualiquantitativa) resvala em argumentos frágeis ou equivocados, que retiram de cada uma a força e o desempenho potencial que podem oferecer. A abordagem quantitativa deve ser utilizada em investigações cuja perspectiva se coloca na descrição e interpretação de fenômenos, através de significados explícitos, objetivos e lastreados pelo número de ocorrências. É considerada como inerente aos objetos e atos (fatos). Permite abordagens focais e estruturadas, resultantes de dados coletados através de perguntas cujas respostas são pré-determinadas, "pré-vistas" e "pré-paradas" (fechadas). 0 método de análise dos dados é eminentemente dedutivo, partindo de geral para o particular, e orientado para resultados que possam ser generalizados.

Já o olhar qualitativo busca descrever significados socialmente construídos de forma a proporcionar um entendimento mais profundo e intrínseco de um fenômeno e que faça sentido quanto às ligações entre elementos. Através de perspectivas subjetivas e orientadas aos processos internos do objeto observado, visa identificar, compreender, interpretar, descrever e desenvolver conceitos e teorias sobre o significado e o caráter dos fenômenos. Privilegia as características não estruturadas, é rico em detalhes e enfatiza as interações. A coleta de dados se dá através de instrumentos semiestruturados ou não estruturados que oferecem respostas discursivas e abertas. 0 método de análise é indutivo, dialético, orientado ao processo, e os resultados não são generalizáveis.

Apesar da histórica oposição e exclusividade entre abordagens quantitativas (experimentais e objetivas) e as abordagens qualitativas (interpretativas e subjetivas), a modernidade tratou de flexibilizar tais posturas de forma a permitir procedimentos metodológicos combinados e que possibilitem estudos mais significativos quaisquer que sejam as perspectivas e áreas do conhecimento. Nas abordagens mistas (quali-quanti) os elementos característicos de cada uma são combinados para permitir avaliações externas (de forma) e internas (de conteúdo) de situações-problema que necessitem, complementar e concomitantemente, de ambas as leituras.

Uma ocorrência frequente é confundir a abordagem com a natureza do dado utilizado. Dados quantitativos são resultantes de avaliações objetivas, cuja escala utilizada mede diretamente a ocorrência da variável (por exemplo: peso, renda, receita etc.), enquanto que os dados qualitativos têm origem em apreciações subjetivas e valorações coletadas através de opiniões e percepções (por exemplo: satisfação, rejeição etc.). No entanto, abordagens quantitativas podem valer-se de dados qualitativos, assim como as qualitativas podem fazer uso de dados quantitativos para auxiliar a interpretação do pesquisador, ampliando suas possibilidades de análise e interpretação de fenômenos.

Uma vez definida a abordagem é necessário escolher o tipo de pesquisa a ser desenvolvida - exploratória, descritiva ou explicativa/causal - em função dos objetivos da investigação. A pesquisa exploratória é orientada para um campo, assunto ou aspecto inédito de um fenômeno ou situação sobre o qual existe pouco ou nenhum conhecimento acumulado. Esse tipo de estudo não tem como objetivo o teste de hipóteses. Quando muito, são estabelecidos pressupostos de pesquisa. Um cuidado especial deve ser tomado ao se declarar uma pesquisa como exploratória, geralmente escolhida pelo ineditismo ou novidade do assunto. A pesquisa exploratória também serve como base de sustentação inicial a estudos mais aprofundados e sistemáticos.

A pesquisa descritiva, como o próprio nome declara, visa descrever objetos, situações ou fenômenos através de observações e medições detalhadas acerca 
de seus comportamentos e/ou características de forma a determinar-lhes um perfil, uma classificação de conduta, atitude ou estado. Nesse caso, as hipóteses - respostas ou definições provisórias e antecipadas ao(s) problema(s) de estudo - assim como as variáveis de pesquisa devem ser estabelecidas com cuidado e competência pela relação de associação e/ou de dependência que guardam entre si, implicando diretamente na consecução de resultados.

Já a pesquisa explicativa ou causal verifica a existência de relações de causa e efeito entre variáveis, ou seja, a identificação de fatores que determinam a ocorrência de fenômenos. Também se prestam a confirmar ou refutar uma relação teórica ainda não verificada empiricamente. No atendimento aos seus objetivos, além da atenção especial ao estabelecimento de hipóteses e variáveis, via de regra há que se investir recursos significativos de tempo, dinheiro, pessoal e tecnologia, além de expectativas, é claro!

Após a determinação da tipologia da pesquisa é necessário eleger as técnicas adequadas e coerentes com as escolhas iniciais. Existem as técnicas baseadas em análise de documentos, caracterizados pelos levantamentos bibliográficos, pesquisas documentais e estatísticas, que utilizam dados secundários, coletados e interpretados por outrem. As técnicas empíricas produzem dados primários, resultantes de observações inéditas como o estudo de caso, a observação participante, os levantamentos e estudos de campo, assim como os experimentos de laboratório, entre outros. Os instrumentos de coleta de dados (questionários, formulários, entrevistas, entre outros) devem ser construídos de acordo como a abordagem e o tipo de pesquisa que se pretende realizar.

\section{Metodologia nos anais do ENEGEP}

Em consonância com os objetivos e a classificação utilizados por Berto e Nakano (2000) e Nakano (2011) e para permitir a comparação dos dados, neste estudo foi novamente utilizada a tipologia de Filippini (1997) para a divisão das técnicas de pesquisa. A classificação se refere às técnicas de pesquisa - muitas vezes denominadas, inadequadamente, de métodos - mais usuais no desenvolvimento de pesquisas em Engenharia de Produção e agrupadas em função de abordagem qualitativa, quantitativa ou mista. As técnicas são:

- Levantamento (survey) - investigação que privilegia a coleta de dados quantitativos oriundos de grandes amostras, com a aplicação de técnicas de amostragem, análise e inferência estatística assim como a utilização de instrumento de coleta de dados único (em geral formulário ou questionário);
- Estudo de caso - descrição e análise aprofundada de um ou mais objetos de observação (casos), com o uso de múltiplos instrumentos de coleta de dados, podendo incluir a interação entre pesquisador e objeto de pesquisa;

- Modelagem (ou modelamento) - uso de técnicas matemáticas para elaborar um modelo matemático ou descrever o funcionamento de um sistema produtivo ou parte dele;

- Simulação - uso de técnicas matemáticas e computacionais para simular o funcionamento de sistemas produtivos;

- Estudo de campo - emprego de outros métodos de pesquisa (principalmente com dados primários de natureza qualitativa) ou uso de dados primários sem estruturação formal do método de pesquisa;

- Experimento - estudo de relações de causa e efeito entre duas ou mais variáveis sob condições controladas pelo pesquisador; e

- Teórico-conceitual - textos, discussões, análises e/ou proposições conceituais de natureza monográfica a partir da literatura publicada e revisões bibliográficas, sem a presença de dados de campo.

\section{Metodologia utilizada no estudo}

Foram analisados 6.987 textos, obtidos a partir dos anais ENEGEP de 1996 a 2007 publicados em suporte digital (CD-ROM). Como nas análises anteriores, o número não correspondeu à totalidade dos trabalhos publicados devido à ocorrência de problemas com as mídias físicas utilizadas. 0 levantamento como um todo foi efetuado em três etapas, em períodos e por pessoas diferentes. 0 primeiro, de 1996 a 1998, foi feito pelos próprios autores (BERTO; NAKANO, 1998; 2000). Os levantamentos referentes aos períodos de 1999 a 2004 e de 2005 a 2007 foram efetuados por assistentes diferentes, em ocasiões distintas (NAKANO, 2011).

A identificação do tipo de pesquisa e da técnica empregada foi feita através da leitura dos resumos e das seções introdutórias de cada artigo, aceitando-se a declaração dos autores quanto ao método/técnica de pesquisa empregado. Quando o exame inicial foi considerado insuficiente para a classificação, as demais seções dos artigos foram examinadas. Como no passado, não houve julgamento quanto à adequação do tipo de pesquisa ou técnica declarados no texto do trabalho.

A classificação efetuada pelos assistentes aconteceu em dois períodos distintos e, em ambos, o procedimento foi iniciado com o estudo de um manual de metodologia de pesquisa pelos mesmos, que então foram instruídos sobre a classificação 
utilizada por Filippini (1997). Complementando o seu treinamento, os assistentes leram as primeiras publicações dos autores sobre o assunto e foram alertados sobre as principais dificuldades passiveis de serem encontradas durante o processo de classificação. Em cada um dos períodos, os autores e o assistente envolvido selecionaram uma amostra aleatória de aproximadamente 40 artigos dos anais a serem examinados. Cada lote foi classificado independentemente pelos autores e pelo assistente. Os resultados das classificações foram comparados e as diferenças foram conciliadas e ajustadas. No caso de um dos assistentes, devido ao volume de divergências, uma segunda amostra foi selecionada e novamente classificada independentemente. Desta feita, a quantidade de divergências caiu significativamente, o que permitiu o início da classificação dos artigos. Durante o processo classificatório, cada assistente foi instruído a indicar todas as dúvidas e dificuldades de classificação encontradas, que foram periodicamente examinadas e discutidas uma a uma com os autores.

\section{Análise e discussão dos resultados}

Os resultados obtidos são apresentados e discutidos abaixo. A Tabela 1 e a Figura 1 organizam e consolidam os dados coletados e categorizados da massa de artigos analisados.
0 número total de trabalhos apresentados é crescente e até certo ponto espelha o crescimento do evento e da própria Engenharia de Produção. Os anos da década de 1990 (inclusive o ano 2000) respondem por 2.254 artigos (Tabela 1) e os anos 2000 pelos 4.733 restantes (Figura 1). Do total de 6.987 artigos: 11,8\% são de Modelagem e Simulação; 5,9\% utilizam Survey, 25,9\%, o Estudo de caso; 18\% são Estudos de campo; 1,7\% são Experimentos; e 36,7\%, trabalhos Teórico-conceituais.

Considerando-se os números totais do período, os estudos de natureza teórico-conceitual ainda são maioria. Porém há que se atentar para o crescimento significativo da pesquisa empírica, já percebido e apontado por Nakano (2011) em avaliação anterior. Somando-se todas as técnicas que envolvem coleta e análise de dados (experimento, survey, estudo de campo e estudo de caso), o aumento ocorrido é nítido, verificando-se o predomínio claro dos trabalhos empíricos a partir de 2004. Dessa forma, nos 12 anos cobertos pela análise, a proporção se inverteu: se na década de 1990 cerca de 50\% dos artigos eram de natureza teórico-conceitual, nos anos 2000 a proporção de artigos empíricos passa a $60 \%$. A Figura 2 ilustra o crescimento e a inversão na proporção de artigos teóricos e empíricos.

Tabela 1. Técnicas de pesquisa utilizadas nos trabalhos dos anais do ENEGEP de 1996 a 2007.

\begin{tabular}{|c|c|c|c|c|c|c|c|c|}
\hline \multirow[b]{2}{*}{ Ano } & \multirow{2}{*}{$\begin{array}{c}\text { Número de } \\
\text { artigos }\end{array}$} & \multicolumn{7}{|c|}{ Técnica de pesquisa } \\
\hline & & Modelagem & Simulação & Survey & $\begin{array}{l}\text { Estudo de } \\
\text { caso }\end{array}$ & $\begin{array}{l}\text { Estudo de } \\
\text { campo }\end{array}$ & Experimento & $\begin{array}{l}\text { Teórico- } \\
\text { conceitual }\end{array}$ \\
\hline \multirow[t]{2}{*}{1996} & 599 & 76 & 16 & 18 & 101 & 89 & 9 & 290 \\
\hline & & $12,70 \%$ & $2,70 \%$ & $3,00 \%$ & $16,90 \%$ & $14,90 \%$ & $1,5 \%$ & $48,4 \%$ \\
\hline \multirow[t]{2}{*}{1997} & 473 & 78 & 20 & 23 & 67 & 92 & 11 & 182 \\
\hline & & $16,50 \%$ & $4,20 \%$ & $4,9 \%$ & $14,2 \%$ & $19,5 \%$ & $2,3 \%$ & $38,5 \%$ \\
\hline \multirow[t]{2}{*}{1998} & 538 & 67 & 18 & 26 & 75 & 89 & 4 & 259 \\
\hline & & $12,50 \%$ & $3,30 \%$ & $4,8 \%$ & $13,9 \%$ & $16,0 \%$ & $0,7 \%$ & $48,1 \%$ \\
\hline \multirow[t]{2}{*}{1999} & 398 & 19 & 11 & 8 & 102 & 35 & 7 & 216 \\
\hline & & $4,80 \%$ & $2,80 \%$ & $2,0 \%$ & $25,6 \%$ & $8,8 \%$ & $1,8 \%$ & $54,3 \%$ \\
\hline \multirow[t]{2}{*}{2000} & 246 & 15 & 13 & 13 & 65 & 25 & 3 & 112 \\
\hline & & $6,1 \%$ & $5,3 \%$ & $5,3 \%$ & $26,4 \%$ & $10,2 \%$ & $1,2 \%$ & $45,5 \%$ \\
\hline \multirow[t]{2}{*}{2001} & 548 & 21 & 28 & 22 & 161 & 49 & 10 & 257 \\
\hline & & $3,8 \%$ & $5,1 \%$ & $4,0 \%$ & $29,4 \%$ & $8,9 \%$ & $1,8 \%$ & $46,9 \%$ \\
\hline \multirow[t]{2}{*}{2002} & 598 & 23 & 19 & 21 & 176 & 87 & 12 & 260 \\
\hline & & $3,8 \%$ & $3,2 \%$ & $3,5 \%$ & $29,4 \%$ & $14,5 \%$ & $2,0 \%$ & $43,5 \%$ \\
\hline \multirow[t]{2}{*}{2003} & 667 & 28 & 36 & 28 & 216 & 132 & 10 & 217 \\
\hline & & $4,2 \%$ & $5,4 \%$ & $4,2 \%$ & $32,4 \%$ & $19,8 \%$ & $1,5 \%$ & $32,5 \%$ \\
\hline \multirow[t]{2}{*}{2004} & 688 & 23 & 67 & 27 & 225 & 130 & 9 & 207 \\
\hline & & $3,3 \%$ & $9,7 \%$ & $3,9 \%$ & $32,7 \%$ & $18,9 \%$ & $1,3 \%$ & $30,1 \%$ \\
\hline \multirow[t]{2}{*}{2005} & 695 & 36 & 24 & 66 & 206 & 161 & 19 & 183 \\
\hline & & $5,2 \%$ & $3,5 \%$ & $9,5 \%$ & $29,6 \%$ & $23,2 \%$ & $2,7 \%$ & $26,3 \%$ \\
\hline \multirow[t]{2}{*}{2006} & 765 & 48 & 39 & 83 & 214 & 180 & 14 & 187 \\
\hline & & $6,3 \%$ & $5,1 \%$ & $10,8 \%$ & $27,9 \%$ & $23,4 \%$ & $1,8 \%$ & $24,4 \%$ \\
\hline \multirow[t]{2}{*}{2007} & 772 & 53 & 44 & 79 & 200 & 192 & 11 & 193 \\
\hline & & $6,9 \%$ & $5,7 \%$ & $10,2 \%$ & $25,9 \%$ & $24,9 \%$ & $1,4 \%$ & $25,0 \%$ \\
\hline
\end{tabular}


Por outro lado, embora a proporção de artigos teóricos tenha caído à metade, a comparação com dados internacionais revela que a taxa ainda é muito elevada. Nos 14 volumes do periódico Production and Operations Management (POM), de 1992 até 2005, foram publicados 399 artigos, divididos em 56 números. Desses, 38,8\% contêm dados empíricos, $38,1 \%$ são de modelagem matemática e métodos analíticos e 16,2\% são artigos conceituais e revisões de literatura, sendo que os 6,9\% restantes se referem ao ensino de engenharia (GUPTA; VERMA; VICTORINO, 2006). Se os artigos sobre ensino de engenharia forem retirados da amostra, a proporção fica: 41,7\% de artigos empíricos, 40,9\% de artigos de modelagem e somente 10,5\% de artigos teóricos.

Analisando-se os 6.987 artigos publicados em 12 anos no ENEGEP, a proporção é a seguinte: 51,6\% de artigos empíricos, $11,8 \%$ de modelagem e 36,7\% de teóricos. A proporção de artigos teórico-conceituais, mesmo com a redução, ainda é muito elevada, representando o dobro do número presente em um periódico de primeira linha como o POM (classificação Qualis A1).

Da mesma forma é notável a pequena incidência de artigos de modelagem matemática e métodos analíticos, embora nesse caso possa se conjecturar que esses trabalhos sejam apresentados em congressos específicos, como o da Sociedade Brasileira de Pesquisa Operacional (SOBRAPO). A proporção por ano dos artigos, divididos entre empíricos, teóricos e de modelagem é apresentada na Tabela 2 .

Quanto às abordagens de pesquisa, a predominância das técnicas de origem qualitativa é marcante, como mostra a Tabela 3. Do total de trabalhos analisados

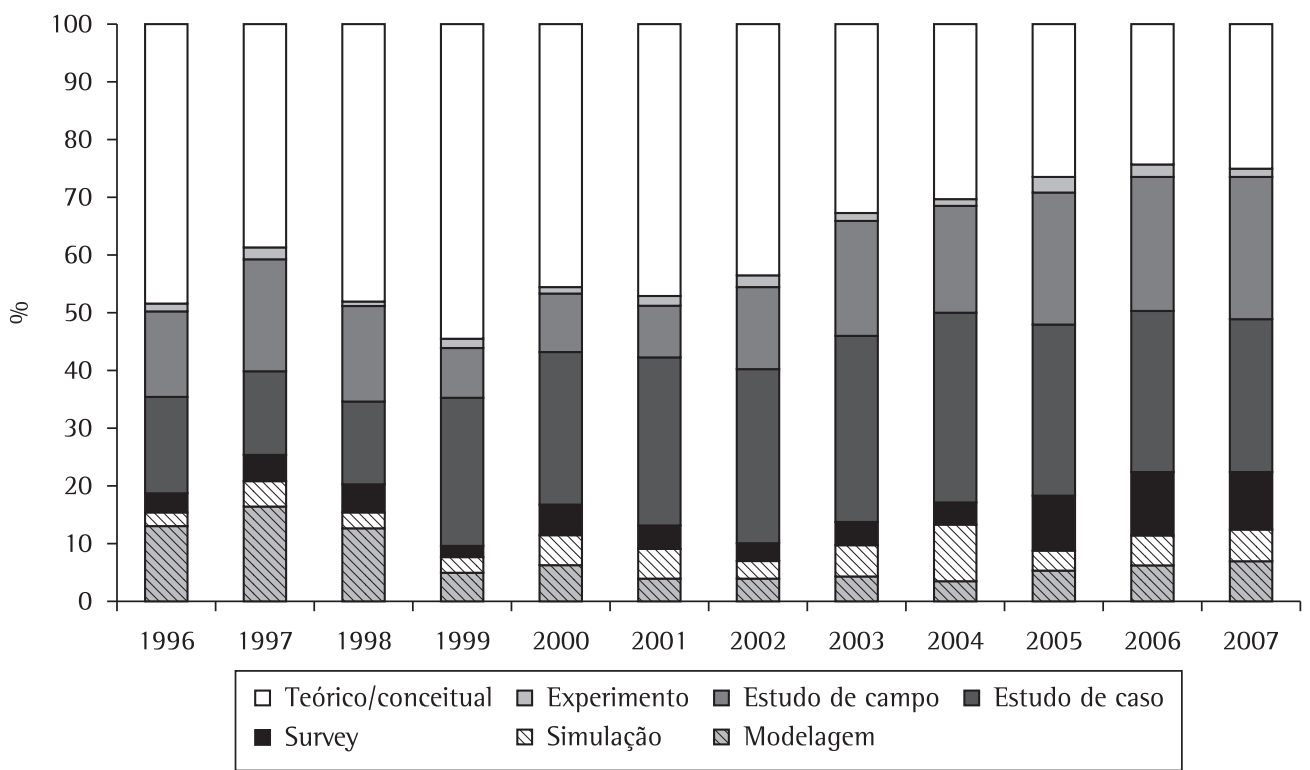

Figura 1. Técnicas de pesquisa utilizadas nos trabalhos dos anais do ENEGEP - 1996-2007. Fonte: Os autores.

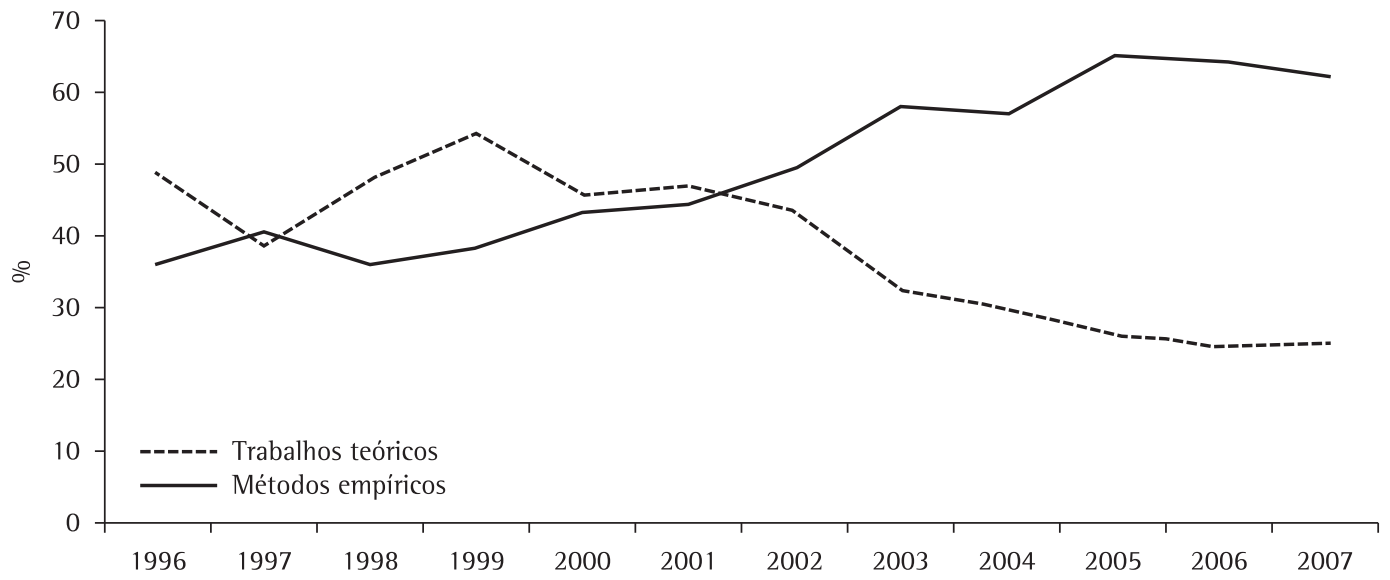

Figura 2. Proporção de artigos teóricos e empíricos. Fonte: Os autores. 
Tabela 2. Artigos empíricos, teóricos e de modelagem publicados por ano comparados a dados internacionais.

\begin{tabular}{|c|c|c|c|c|c|c|}
\hline \multirow{2}{*}{ Ano } & \multicolumn{2}{|c|}{ Estudos empíricos } & \multicolumn{2}{|c|}{ Estudos teóricos } & \multicolumn{2}{|c|}{ Modelagem e métodos analíticos } \\
\hline & $\#$ & $\%$ & $\#$ & $\%$ & $\#$ & $\%$ \\
\hline 1996 & 217 & 36,2 & 290 & 48,4 & 92 & 15,4 \\
\hline 1997 & 193 & 40,8 & 182 & 38,5 & 98 & 20,7 \\
\hline 1998 & 194 & 36,1 & 259 & 48,1 & 85 & 15,8 \\
\hline 1999 & 152 & 38,2 & 216 & 54,3 & 30 & 7,5 \\
\hline 2000 & 106 & 43,1 & 112 & 45,5 & 28 & 11,4 \\
\hline 2001 & 242 & 44,2 & 257 & 46,9 & 49 & 8,9 \\
\hline 2002 & 296 & 49,5 & 260 & 43,5 & 42 & 7,0 \\
\hline 2003 & 386 & 57,9 & 217 & 32,5 & 64 & 9,6 \\
\hline 2004 & 391 & 56,8 & 207 & 30,1 & 90 & 13,1 \\
\hline 2005 & 452 & 65,0 & 183 & 26,3 & 60 & 8,6 \\
\hline 2006 & 491 & 64,2 & 187 & 24,4 & 87 & 11,4 \\
\hline 2007 & 482 & 62,4 & 193 & 25,0 & 97 & 12,6 \\
\hline Total & 3.602 & 51,6 & 2.563 & 36,7 & 822 & 11,8 \\
\hline Р0M 1992-2005 & & 41,7 & & 10,5 & & 40,9 \\
\hline
\end{tabular}

Fonte: Os autores e dados adaptados de Gupta, Verma e Victorino (2006).

em 12 anos, nada menos de $85 \%$ as utilizam (foram considerados técnicas qualitativas o Estudo de caso e os Estudos de campo e como técnicas quantitativas o survey e o experimento).

Se comparados ao padrão de produção internacional encontrado na literatura, o dos trabalhos apresentados no ENEGEP difere substancialmente uma vez que apresenta menor utilização das técnicas de levantamento (survey), de enfoque quantitativo e uso intensivo do estudo de caso, de natureza qualitativa. Para os dados internacionais, ver Gupta, Verma e Victorino (2006) e Zhao, Flynn e Roth (2007).

A Tabela 4 indica que embora a utilização do estudo de caso tenha caído, ele continua a ser o método mais utilizado nos trabalhos publicados, o que indica a preferência dos autores por esse método de abordagem qualitativa.

Uma questão pertinente relaciona-se à propriedade com que as escolhas das abordagens de pesquisa são efetuadas, em particular as de natureza qualitativa. Embora se possa lembrar que a comparação da Tabela 4 é limitada, pois o uso de técnicas quantitativas é frequente (e incentivado) nos circuitos acadêmicos norte-americanos, e que os dados internacionais apresentados se referem a periódicos - o que explicaria em parte as discrepâncias -, reafirma-se aqui a preocupação quanto ao emprego das abordagens qualitativas, principalmente quando a escolha se dá não pela sua adequação ao objetivo da pesquisa mas pela sua aparente facilidade de aplicação e flexibilidade.

0 Estudo de caso é particularmente enganador: a relativa facilidade de se visitar uma empresa e de conseguir algumas entrevistas (principalmente quando há algum tipo de contato anterior) leva, em muitos casos, à equivocada impressão de que seja de mais fácil aplicação do que, por exemplo, um survey. As técnicas qualitativas também são muitas vezes escolhidas a partir da falsa impressão de terem custos menores. Porém, a avaliação pode ser errônea: um estudo de
Tabela 3. Quantidade e proporção de técnicas quantitativas e qualitativas utilizadas nos trabalhos publicados nos anais do ENEGEP.

\begin{tabular}{ccccc}
\hline \multirow{2}{*}{ Ano } & \multicolumn{2}{c}{ Técnicas quantitativas } & \multicolumn{2}{c}{ Técnicas qualitativas } \\
\cline { 2 - 5 } & $\#$ & $\%$ & $\#$ & $\%$ \\
\hline 1996 & 27 & 12,4 & 190 & 87,6 \\
1997 & 34 & 17,6 & 159 & 82,4 \\
1998 & 30 & 15,5 & 164 & 84,5 \\
1999 & 15 & 9,9 & 137 & 90,1 \\
2000 & 16 & 15,1 & 90 & 84,9 \\
2001 & 32 & 13,2 & 210 & 86,8 \\
2002 & 33 & 11,2 & 263 & 88,9 \\
2003 & 38 & 9,8 & 348 & 90,2 \\
2004 & 36 & 9,2 & 355 & 90,8 \\
2005 & 85 & 18,8 & 367 & 81,2 \\
2006 & 97 & 19,8 & 394 & 80,2 \\
2007 & 90 & 18,7 & 392 & 81,3 \\
\hline
\end{tabular}

Fonte: Os autores.

caso adequadamente conduzido exige planejamento, elaboração de critérios claros de análise, grande esforço na coleta de dados e rigor na sua posterior análise sob o risco de resultar, quando esses cuidados não são tomados, somente em um relato coloquial, um “causo", de valor acadêmico limitado. É preciso manter o rigor na análise dos dados textuais obtidos por uma técnica qualitativa através da análise de conteúdo, para que a interpretação obtida seja sólida e robusta ao questionamento (DENZIN; LINCOLN, 2008).

Por outro lado, embora aparentemente de aplicação mais difícil, as pesquisas quantitativas oferecem menor dificuldade no manuseio dos dados: além dos construtos e as variáveis já estarem definidos nas hipóteses, a análise não exige do pesquisador o ônus da interpretação subjetiva, mas a aplicação de técnicas estatísticas, atualmente facilitada pelo acesso a softwares específicos que poupam o trabalho de cálculos complexos. Resta a ele a correta e criativa interpretação dos resultados baseada em sua revisão teórico-conceitual. Assim, da mesma forma que nas 
Tabela 4. Comparação da ocorrência das técnicas de Surveye Estudo de caso - ENEGEP versus dados internacionais.

\begin{tabular}{cccc}
\hline \multicolumn{3}{c}{ Dados da literatura internacional } \\
\hline Método de pesquisa & $\begin{array}{c}\text { Zhao, Flynn e Roth (2007) } \\
(\%)\end{array}$ & $\begin{array}{c}\text { POM (1992-2005) } \\
\text { Gupta, Verma e Victorino (2006) } \\
(\%)\end{array}$ & $\begin{array}{c}\text { ENEGEP (1996-2007) } \\
(\%)\end{array}$ \\
\hline Estudo de caso & 12,8 & 14 & 50,2 \\
Survey & 77,1 & 28 & 11,5 \\
Outros & 10,1 & 58 & 38,3 \\
\hline
\end{tabular}

Fonte: Os autores e dados adaptados de Gupta, Verma e Victorino (2006) e Zhao, Flynn e Roth (2007).

técnicas qualitativas, a habilidade, o conhecimento e o talento do pesquisador farão diferença na análise, elaboração e comunicação dos resultados.

\section{Conclusão}

Os dados levantados mostram o efetivo crescimento na publicação de trabalhos empíricos em detrimento daqueles resultantes de pesquisas teóricas. Se, no final da década de 1990 eles representavam a metade dos trabalhos publicados nos anais do ENEGEP, 12 anos depois representam três quartos da produção acadêmica registrada na referida fonte. Como ressaltado em Nakano (2011), o aumento de trabalhos empíricos é um excelente sinal, indício do esforço da comunidade em produzir trabalhos baseados em dados e pesquisa de campo, indício de um alinhamento à produção da literatura internacional que demanda e valoriza sobremaneira a pesquisa empírica na área de operações (BOYER; SWINK, 2008).

Por outro lado, permanece, e cresceu significativamente, a preferência pelo Estudo de caso. Não há, em princípio, problema algum no uso da técnica, mas dois aspectos destoantes chamam a atenção dos observadores. Em primeiro lugar, a diferença em relação à literatura internacional: mesmo considerando que a literatura norte-americana tradicionalmente privilegia métodos quantitativos, o contraste é marcante. Corroborando as indicações de Nakano (2011), isso pode significar uma barreira à aspiração dos autores nacionais em publicar seus trabalhos em âmbito internacional, exigência dos programas de pós-graduação, das agências de fomento, além de principal indicador de produção científica qualificada. Em segundo lugar, além do já comentado sobre a escolha de técnicas qualitativas, o alerta emitido na década passada (BERTO; NAKANO, 2000) continua importante: o uso inadequado do Estudo de caso pode comprometer a qualidade da produção acadêmica da engenharia de produção nacional. Um maior número de estudos quantitativos pode aumentar significativamente as chances da pesquisa brasileira em engenharia de produção se fazer presente em repositórios consagrados e publicações internacionais de reconhecida importância.

0 exame de textos pelos autores, principalmente aqueles nos quais os assistentes tiveram maior dificuldade de classificação, mostrou mais um aspecto a ser considerado: parte do que se publica como resultado de pesquisa deveria, na realidade, ser considerado relato de experiência ou, ainda, relatório técnico. Esses trabalhos contêm dados de campo, em geral informações sobre as empresas que focalizam, mas carecem de base teórico-conceitual mínima. Limitam-se a apresentar soluções encontradas para os problemas empresariais que, sem desmerecer o seu valor e importância na disseminação, não deveriam ser considerados "de natureza científica", uma vez que não oferecem discussão conceitual apropriada e/ou contribuição à teoria. Esses textos, que foram contados na categoria Estudos de campo, rigorosamente deveriam ser considerados relatórios técnicos e teriam chance reduzida de publicação em periódicos de maior expressão. A presença desse tipo de texto pode indicar mais uma deficiência a ser tratada na preparação de pesquisadores: o esclarecimento do que se constitui uma contribuição teórica e da importância de sua presença em textos que almejem publicação em periódicos mais qualificados.

Observa-se que, apesar dos progressos significativos na disseminação e na observação do escopo conceitual da metodologia científica, enquanto disciplina a ser ensinada, aprendida e praticada, ainda existem lacunas e descontinuidades a corrigir, a começar pela própria escolha das abordagens de pesquisa utilizadas pelos pesquisadores. 0 crescimento no número de trabalhos empíricos precisa agora ser equilibrado pelo aumento da sua qualidade. 0 avanço na qualidade é difícil de ser julgado, mas a presença crescente de trabalhos nacionais em periódicos qualificados é indicativo seguro dessa melhoria, inclusive em termos de aparato metodológico.

Os autores esperam que, na década e meia durante a qual publicaram os levantamentos da produção científica da Engenharia de Produção, tenham contribuído de alguma forma para sua evolução. Nos anos 90, quando as observações foram iniciadas, a pesquisa empírica nacional carecia de quantidade e qualidade. Hoje, a primeira deficiência foi em grande parte superada, porém resta a segunda, que talvez seja o maior desafio para a comunidade.

Entre os pontos de atenção para os formadores de recursos humanos são passíveis de destaque: a) maior discussão e aprofundamento sobre o que se 
constitui uma contribuição teórica, como sugerem Whetten (2003) e Caldas (2003), Sutton e Staw (1995); assim como b) a necessidade de treinamento no planejamento e nas abordagens de pesquisa mencionadas em Fleury (2011) e Martins (2011), que resultem na correta aplicação das técnicas, tanto quantitativas (com cuidado especial para o Estudo de caso), como nas qualitativas. Quanto às últimas, é importante a elaboração de projetos de pesquisa com objetivos que acomodem a aplicação tanto de técnicas mais simples quanto de mais sofisticadas.

Finalmente, os autores também veem com satisfação que, se há 25 anos o pioneiro ENEGEP era o único canal brasileiro de difusão da produção acadêmica da Engenharia de Produção, hoje a realidade é diferente: outros eventos nacionais de porte se consolidaram, o evento internacional nascido dentro do próprio ENEGEP se emancipou e a comunidade tem presença constante em diversos eventos internacionais. Por esse motivo, os autores consideram que o ciclo das suas observações, iniciado em 1998, se encerra com este levantamento, e que o acompanhamento da produção nacional exige agora novos pontos de observação.

\section{Referências}

BERTO, R. M. V. S.; NAKANO, D. N. Metodologia da pesquisa e a Engenharia de Produção ln: ENCONTRO NACIONAL DE ENGENHARIA DE PRODUÇÃO, 18., 1998, Niterói. Anais... Niterói: ABEPRO, 1998. 1 CD-ROM.

BERTO, R. M. V. S.; NAKANO, D. N. A produção científica nos Anais do Encontro Nacional de Engenharia de Produção: um levantamento de métodos e tipos de pesquisa. Produção, v. 9, n. 2, p. 65-76, 2000. http://dx.doi. org/10.1590/S0103-65131999000200005

BOFF, L. Saber cuidar. a ética do humano - compaixão pela terra. 8. ed. São Paulo: Vozes, 2002.

BOYER, K. K.; SWINK, M. L. Empirical elephants: why multiple methods are essential to quality research in operations and supply chain management. Journal of Operations Management, v. 26, n. 3, p. 337-348, 2008. http:/l dx.doi.org/10.1016/j.jom.2008.03.001
CALDAS, M. P. Contribuição teórica: como assim, cara pálida? Revista de Administração de Empresas, v. 43, n. 3, p. 65-68, 2003. http://dx.doi.org/10.1590/S003475902003000300006

DENZIN, N. K.; LINCOLN, Y. (Eds.). The landscape of qualitative research: theories and issues. 3rd ed. Thousand Oaks: Sage, 2008. PMid:19019088.

FLEURY, A. Planejamento do projeto de pesquisa e definição do modelo teórico. In: CAUCHICK, P. M. (Coord.). Metodologia de pesquisa em Engenharia de Produção e Gestão de Operações. Rio de Janeiro: Elsevier, 2011.

FILIPPINI, R. Operations management research: some reflections on evolution, models and empirical studies in OM. International Journal of Operations and Production Management, v. 17, n. 7, p. 655-70, 1997. http://dx.doi. org/10.1108/01443579710175583

GUPTA, S.; VERMA, R.; VICTORINO, L. Empirical research published in Production and Operations Management (1992-2005): trends and future research directions. Production and Operations Management, v. 15, n. 3, p. 432-448, 2006. http://dx.doi. org/10.1111/j.1937-5956.2006.tb00256.x

MARTINS, R. A. Abordagens quantitativa e qualitativa. In: CAUCHICK, P. M. (Coord.). Metodologia de pesquisa em Engenharia de Produção e Gestão de Operações. Rio de Janeiro: Elsevier, 2011.

NAKANO, D. Métodos de pesquisa adotados na Engenharia de Produção e Gestão de Operações. In: CAUCHICK, P. M. (Coord.). Metodologia de pesquisa em Engenharia de Produção e Gestão de Operações. Rio de Janeiro: Elsevier, 2011.

SUTTON, R. 1.; STAW, B. M. What theory is not. Administrative Science Quarterly, v. 40, n. 3, p. 371-385, 1995. http:// dx.doi.org/10.2307/2393788

TURATO, E. R. Métodos qualitativos e quantitativos na área da saúde: definições, diferenças e seus objetos de pesquisa. Revista de Saúde Pública, v. 39, n. 3, jun. 2005. http:// dx.doi.org/10.1590/S0034-89102005000300025

WHETTEN, D. A. 0 que constitui uma contribuição teórica? Revista de Administração de Empresas, v. 43, n. 3, p. 69-73, 2003.

ZHAO, X.; FLYNN, B. B.; ROTH, A. V. Decision sciences research in china: current status, opportunities, and propositions for research in supply chain management, logistics, and quality management. Decision Sciences, v. 38, n. 1, p. 39-80, 2007. http://dx.doi.org/10.1111/ j.1540-5915.2007.00148.x

\title{
Revisiting scholarly output in the records of the Brazilian Meeting of Industrial Engineering
}

\begin{abstract}
This paper is the final step of a longitudinal study on research methodology in the papers published in the Brazilian Meeting of Industrial Engineering - ENEGEP Annals. Starting with a brief discussion on quantitative and qualitative research traditions and the choice of research methods and data collection techniques, papers published in the ENEGEP for the past 12 years, from 1996 to 2007, were examined and sorted following the classification proposed by Fillipini (1997). Results indicated strong empirical research growth, but an enduring difference on the adoption of research methods as compared to international literature.
\end{abstract}

\section{Keywords}

Research methods. Research methodology. Production engineering. Industrial engineering. 